\title{
Metabolic transition of milk triacylglycerol synthesis in response to varying levels of palmitate in porcine mammary epithelial cells
}

Yantao Lv $v^{1,3}$, Shihai Zhang ${ }^{1}$, Wutai Guan ${ }^{1,2^{*}}$, Fang Chen ${ }^{1}$, Yinzhi Zhang ${ }^{1}$, Jun Chen ${ }^{1}$ and Yang Liu ${ }^{1}$

\begin{abstract}
Background: Milk in mammals is a key source of lipids for offspring, providing both critical energy and essential fatty acids. For lactating sows, palmitic acid is one of the most abundant fatty acids in milk, providing 10 12\% of the suckling pig total dietary energy supply. However, the effects of exogenous palmitic acid on milk fat synthesis in sow mammary glands are not well-known. In this study, we investigated the effects of palmitic acid on lipogenic genes in porcine mammary epithelial cells (pMECs) to explore the role of exogenous palmitic acid in mediating milk triacylglycerols (TAG) synthesis.

Methods: Porcine mammary epithelial cells were cultured for $24 \mathrm{~h}$ in the presence of different concentrations of palmitate $(0,25,50,100,200,400$, and $600 \mu \mathrm{M})$. The effect of palmitate on cell viability was tested via MTT assay. Intracellular lipid accumulation was measured through Oil Red $O$ staining, and TAG levels were quantified by enzymatic colorimetric methods. Expression of genes and proteins involved in milk fat biosynthesis were assayed with quantitative real-time polymerase chain reaction ( $(\mathrm{PCCR})$ and Western blotting, respectively.
\end{abstract}

Results: Incubation with palmitate promoted cellular lipid synthesis in a dose-dependent manner, as reflected by the increased TAG content and enhanced formation of cytosolic lipid droplets. The increased lipid synthesis by palmitate was probably attributable to the upregulated mRNA expression of genes associated with milk fat biosynthesis, including long-chain fatty acid uptake ( $L P L, C D 36)$, intracellular activation and transport (ACSL3, FABP3), TAG synthesis (GPAM, AGPAT6, DGAT1), lipid droplet formation (PLIN2), and regulation of transcription (PPARY). Western blot analysis of CD36 and DGAT1 proteins confirmed the increased lipid synthesis with increasing incubation of palmitate. However, the genes involved in fatty acid de novo synthesis (ACACA, FASM), fatty acid desaturation (SCD), and regulation of transcription (SREBP1, INS/G1) were inversely affected by incubation with increasing concentrations of palmitate. Western blot analysis of ACACA protein confirmed this decrease associated with increasing levels of palmitate.

Conclusions: Results from this study suggest that palmitate stimulated the cytosolic TAG accumulation in pMECs, probably by promoting lipogenic genes and proteins that are involved in lipid synthesis. However, addition of palmitate decreased the fatty acid de novo synthesis in pMECs.

Keywords: Palmitate, Porcine mammary epithelial cells, Milk fat biosynthesis, Lipogenic genes

\footnotetext{
* Correspondence: wtguan@scau.edu.cn

'Guangdong Provincial Key Laboratory of Animal Nutrition Control, College of Animal Science, South China Agricultural University, Guangzhou 510642, People's Republic of China

${ }^{2}$ College of Animal Science and National Engineering Research Center for Breeding Swine Industry, South China Agricultural University, Guangzhou 510642, People's Republic of China

Full list of author information is available at the end of the article
}

(c) The Author(s). 2018 Open Access This article is distributed under the terms of the Creative Commons Attribution 4.0 International License (http://creativecommons.org/licenses/by/4.0/), which permits unrestricted use, distribution, and reproduction in any medium, provided you give appropriate credit to the original author(s) and the source, provide a link to the Creative Commons license, and indicate if changes were made. The Creative Commons Public Domain Dedication waiver (http://creativecommons.org/publicdomain/zero/1.0/) applies to the data made available in this article, unless otherwise stated. 


\section{Background}

Mammalian milk fat is composed of $98 \%$ triacylglycerols (TAG), which are composed of three fatty acids esterified to a three-carbon glycerol backbone [1]. The three most abundant fatty acids in sow milk are palmitic acid (C16:0, 33 wt\%, on average), oleic acid (C18:1, $32 \mathrm{wt} \%$, on average), and linoleic acid (C18:2, $14 \mathrm{wt} \%$, on average) [2]. Palmitic acid represents $20 \sim 30 \%$ of the fatty acids in human and sow milk and $\sim 70 \%$ of palmitic acid is esterified at the sn-2 position of the milk TAG [3-6]. Palmitic acid in milk contributes $10 \sim 12 \%$ of the total dietary energy supply of the suckling offspring [1]. The palmitic acid in the mammary gland has two main origins: (1) de novo synthesis by mammary epithelial cell and (2) release into the circulation from chylomicrons by lipoprotein lipase (LPL) or from adipose tissue by hormone-sensitive lipase (HSL) [7]. Because the palmitic acid from the two main origins is approximately equal, palmitic acid uptake by the mammary gland is an efficient means to modify milk fat content and fatty acid composition in lactating animals. For example, addition of $8 \%$ palm oil (rich in palmitic acid and oleic acid) to the sow diet during lactation significantly increased milk fat concentration and total fatty acids, mainly by increasing the concentration of palmitic acid and oleic acid in milk [8]. Gene expression analysis suggests that lipogenesis in the mammary gland can be modulated by a high-fat diet, with increased dietary fat consumption resulting in a marked decrease in fatty acid synthesis and fewer short-chain fatty acids in milk [9-11].

Since palmitic acid is the most abundant saturated fatty acid in sow diets, and the major fatty acid synthesized de novo, it is important to identify lipogenic genes that are regulated by palmitic acid. In sows, there are few reports in the literature available on the effect of exogenous palmitic acid on metabolic pathway related to milk TAG synthesis. We have previously established the developmental pattern of key factors that channel fatty acids towards milk TAG synthesis in porcine mammary tissue during lactation [2]. Milk fat is synthesized and secreted by specialized secretory epithelial cells that line the luminal cavity of mammary alveoli. Therefore, by using porcine mammary epithelial cells (pMECs) as an in vitro model, we investigated the effects of exogenous palmitate on the two primary pathways for milk lipid synthesis to explore the role of exogenous palmitic acid in mediating milk TAG synthesis.

\section{Methods}

\section{Cell culture}

pMECs were isolated from the mammary gland of a lactating Large White sow on day 17 of lactation and cloned using the method described in Zheng and $\mathrm{He}$ [12]. Briefly, a $1-\mathrm{cm}^{3}$ sample of mammary gland tissue was dissected with sterile scissors into $1-\mathrm{mm}^{3}$ fragments.
The mammary tissue fragments were digested by collagenase II $(500 \mathrm{U} / \mathrm{mL})$ (Sigma-Aldrich, St. Louis, MO, USA) for $1 \mathrm{~h}$ at $37{ }^{\circ} \mathrm{C}$ and $5 \% \mathrm{CO}_{2}$. The isolated cells were cultured in Dulbecco's modified Eagle's medium/F12 (DMEM/F12) (Gibco, Grand Island, NY, USA) media supplemented with $10 \%$ fetal bovine serum (FBS) (Gibco, Grand Island, NY, USA), $5 \mu \mathrm{g} / \mathrm{mL}$ Insulin-Transferrin Selenium (ITS) (ScienCell, Carlsbad, CA, USA), $10 \mathrm{ng} / \mathrm{mL}$ epidermal growth factor (EGF) (Gibco, Grand Island, NY, USA), $10 \mathrm{ng} / \mathrm{mL}$ IGF-1, $5 \mu \mathrm{g} / \mathrm{mL}$ hydrocortisone (Sigma-Aldrich, St. Louis, MO, USA), $100 \mathrm{U} / \mathrm{mL}$ penicillin, and $100 \mu \mathrm{g} / \mathrm{mL}$ streptomycin (Gibco, Grand Island, NY, USA) at $37^{\circ} \mathrm{C}$ in a humidified atmosphere with $5 \% \mathrm{CO}_{2}$. Culture medium was changed every $24 \mathrm{~h}$. Fluorescence-activated cell sorting (FACS) analysis for cytokeratin expression in the cells revealed that they were composed of $90 \%$ mammary epithelial cells. Additionally, the cells had a high mRNA abundance of $\beta$-casein using RT-PCR. In this study, pMECs from the 11th passages were used.

Palmitate ( $\geq 98.5 \%$ pure isomers) (Sigma-Aldrich, St. Louis, MO, USA) used for treatments was conjugated to fatty acid-free bovine serum albumin (BSA) (Equitech-Bio, Kerrville, TX, USA) at a 4:1 ratio.

\section{Cell viability assay}

The effect of palmitate on cell viability was tested via MTT assay. Briefly, pMECs in suspension were seeded at $5 \times 10^{3}$ cells per well in 96-well microtiter plates, and these cells were grown in a humidified atmosphere of $5 \% \mathrm{CO}_{2}$ in air at $37{ }^{\circ} \mathrm{C}$. Then, the cells were exposed to varying concentrations of palmitate $(0,25,50,100,200$, 400 , and $600 \mu \mathrm{M})$ for $24 \mathrm{~h}$. Subsequently, culture medium was carefully removed and exchanged for fresh medium. Twenty microliters of MTT solution $(5 \mathrm{mg} / \mathrm{mL}$ PBS) was then added to each well, and plates were incubated at $37{ }^{\circ} \mathrm{C}$ for $4 \mathrm{~h}$. During incubation, the active enzymes of the viable cells transformed the yellow MTT into insoluble purple formazan crystals. The top medium was then removed, and DMSO was added to each well to dissolve the formazan crystals. The absorbance of the solution was measured at a wavelength of $490 \mathrm{~nm}$ on a multifunctional plate reader.

\section{Assessment of triglyceride storage Intracellular lipid droplet staining}

Intracellular lipid accumulation was measured through Oil Red O staining. pMECs in suspension were seeded at $5 \times 10^{4}$ cells per well in 24-well microtiter plates, and these cells were grown in a humidified atmosphere of $5 \% \mathrm{CO}_{2}$ in air at $37{ }^{\circ} \mathrm{C}$. Cells were then exposed to varying concentrations of palmitate $(0,25,50,100,200,400$, and $600 \mu \mathrm{M})$ for $24 \mathrm{~h}$. Subsequently, the cells were washed with PBS twice, fixed in $4 \%$ paraformaldehyde for $30 \mathrm{~min}$ at room temperature, and then rinsed with 
PBS three times (10 min each time). A 0.5\% Oil Red O/ isopropyl alcohol solution was added for $1 \mathrm{~h}$ to the cells, which were then washed several times with PBS. The stained cytoplasmic lipids were visualized and photographed by an inverted microscope at $\times 400$ magnification. Lipid droplet diameter was measured using Image J software (NIH). In each field captured on camera, the mean diameter of the five largest lipid droplets was calculated and used to estimate the maximum diameter of the intracellular lipid droplet.

\section{Quantification of the intracellular TAG content}

TAG levels were also quantified by enzymatic colorimetric methods using commercial kits (Applygen, Beijing, China). Briefly, pMECs in suspension were seeded at $5 \times 10^{5}$ cells per well in 6-well plates and cultured until 80 90\% confluent. Then, the cells were exposed to varying concentrations of palmitate $(0,25,50,100,200,400$, and $600 \mu \mathrm{M})$ for $24 \mathrm{~h}$. After that, culture medium was carefully removed, and the cells were rinsed with PBS three times. Total protein samples were homogenized in RIPA lysis buffer (Beyotime, Nanjing, China). After centrifugation at 12,000 $\times$ g for $5 \mathrm{~min}$ at $4{ }^{\circ} \mathrm{C}$, the supernatants were collected and stored at $-80{ }^{\circ} \mathrm{C}$ until analysis. TAG contents in supernatant were assayed using commercial kits (Applygen, Beijing, China), and protein concentrations in supernatant were determined using a Pierce BCA protein Assay kit (Thermo Fisher Scientific, Waltham, MA, USA). The TAG contents were normalized for protein in each well and expressed as total TAG per cellular protein. Each experiment was performed in triplicate and repeated a minimum of three times.

\section{RNA extraction and real-time quantitative PCR}

pMECs were seeded at $5 \times 10^{5}$ per well in a 6 -well plate and cultured until 80 90\% confluent. Then, the cells were incubated with increasing concentrations of palmitate $(0,25,50,100,200,400$, and $600 \mu \mathrm{M})$ for $24 \mathrm{~h}$. After that, total RNA was isolated from the cells using TRIzol reagent (Invitrogen, Carlsbad, CA, USA) according to the manufacturer's instructions. Total RNA was purified from contaminating DNA by DNaseItreatment performed on RNeasy columns following the manufacturer's instructions (Takara, Tokyo, Japan). The purity of RNA (A260/A280) for all samples was 1.8 2.0 via a spectrophotometer, indicating that samples were pure and clean. The integrity of the RNA was also checked by ethidium bromide-stained agarose gel electrophoresis. First-strand cDNA synthesis was performed by using a PrimeScript RT reagent kit with gDNA eraser (Takara, Tokyo, Japan). cDNA was then diluted 1:5 with DNase/ RNase-free water.

The mRNA abundance of the reference gene ( $\beta$-actin) and target genes related to lipogenic pathways were determined by quantitative real-time polymerase chain reaction $(q \mathrm{PCR})$. All the primer sequences of $q \mathrm{PCR}$ are shown in Table 1. qPCR was performed using $1 \mu \mathrm{L}$ diluted cDNA combined with $19 \mu \mathrm{L}$ of a mixture composed of $10 \mu \mathrm{L} 1 \times$ SYBR Green Real-Time PCR Master Mix (Toyobo, Tokyo, Japan), $0.5 \mu \mathrm{L}$ of $10 \mu \mathrm{M}$ forward and reverse primer, respectively, and $8 \mu \mathrm{L}$ DNase/RNase-free water in a 96-well reaction plate (Axygen, Tewksbury, MA, USA). $q$ PCR was performed on an ABI Prism 7500 Sequence Detection System using a SYBR ${ }^{\circ}$ PCR protocol. The PCR protocol was composed of an initial denaturation at $95{ }^{\circ} \mathrm{C}$ for $1 \mathrm{~min}$ and 40 cycles of amplification comprising denaturation at $95{ }^{\circ} \mathrm{C}$ for $15 \mathrm{~s}$, annealing at primer-specific temperatures $\left(58 \sim 61{ }^{\circ} \mathrm{C}\right)$ for $15 \mathrm{~s}$ and elongation at $72{ }^{\circ} \mathrm{C}$ for $20 \mathrm{~s}$. Melting curves were analyzed after the reactions. The specificity of the reaction was monitored by determining the product melting curve to avoid nonspecific signals. The amplification of a single product of the expected size was confirmed using 1.5\% agarose gel electrophoresis.

All sample mRNA levels were normalized to the values of the reference gene ( $\beta$-actin), and the results were expressed as fold changes of threshold cycle $(\mathrm{Ct})$ value relative to control using the $2^{-\Delta \Delta \mathrm{Ct}}$ method [13].

\section{Western blot analysis}

pMECs were cultured until 80 90\% confluent and were then incubated with different concentrations of palmitate $(0,25,50,100,200,400$, and $600 \mu \mathrm{M})$ for $24 \mathrm{~h}$. After that, cells were collected and homogenized in RIPA lysis buffer (Beyotime, Nanjing, China) for assay of proteins related to lipogenic pathway. The homogenates were combined with equal volumes of SDS sample buffer, and the proteins were separated by electrophoresis on a $5 \sim 12 \%$ polyacrylamide gel and transferred to nitrocellulose membranes. The membranes were blocked with $5 \%$ skim milk in Tris-buffered saline with Tween, followed by overnight probing with the following primary antibodies: (1) CD36 (N-15) antibody (1:500, Santa Cruz Biotechnology, Santa Cruz, CA, USA), (2) ACACA (T-18) antibody (1:500, Santa Cruz Biotechnology, Santa Cruz, CA, USA), (3) DGAT1 antibody (1:500, Abcam, Cambridge, MA, USA), (4) SREBP1 (C-20) (1:500, Santa Cruz Biotechnology, Santa Cruz, CA, USA), (5) PPAR (T-18) antibody (1:500, Abcam, Cambridge, MA, USA), and (6) $\beta$-actin (C4) antibody (Santa Cruz Biotechnology, Santa Cruz, CA, USA). $\beta$-actin was included as a loading (internal) control. After washing, membranes were incubated with secondary antibody (ABR, Golden, CO, USA). The chemiluminescent signal was detected by using ECL reagents (Beyotime, Nanjing, China), and bands were quantified by Image Processing Software (Image Pro Plus 6.0). 
Table 1 Characteristics of primers used for real-time quantitative PCR analysis

\begin{tabular}{|c|c|c|c|c|}
\hline Gene & NCBI GenBank & Primers $^{a}$ & Primer sequence $\left(5^{\prime} \rightarrow 3^{\prime}\right)$ & Amplicon (bp) \\
\hline \multirow[t]{2}{*}{$L P L$} & NM_214286.1 & F.654 & ATTGCAGGAAGTCTGACCA & 124 \\
\hline & & R.777 & CGTCTACAAAATCTGCGTC & \\
\hline \multirow[t]{2}{*}{ CD36 } & DQ192230.1 & F.433 & GGACTCATTGCTGGTGCTGT & 169 \\
\hline & & R.601 & GTCTGTAAACTTCCGTGCCTGT & \\
\hline \multirow[t]{2}{*}{ ACSL3 } & NM_001143698.1 & F.470 & ACCCTGGATGTGATACGCTA & 150 \\
\hline & & R.619 & AGTTCCCAAGAATAACCTITT & \\
\hline \multirow[t]{2}{*}{ FABP3 } & AY569332.1 & F.157 & CTGGGAGTGGAGTTTGATGAGAC & 164 \\
\hline & & R.320 & CCATGGGTGAGTGTCAGGAT & \\
\hline \multirow[t]{2}{*}{$A C A C A$} & NM_001114269.1 & F.3638 & ACATCCCCACGCTAAACA & 186 \\
\hline & & R.3823 & AGCCCATCACTTCATCAAAG & \\
\hline \multirow[t]{2}{*}{ FASN } & NM_001099930.1 & F.1884 & GCTTGTCCTGGGAAGAGTGTA & 115 \\
\hline & & R.1998 & AGGAACTCGGACATAGCGG & \\
\hline \multirow[t]{2}{*}{$S C D$} & NM_213781.1 & F.785 & TGACCTAAAAGCCGAGAA & 164 \\
\hline & & R.948 & GCACGATGGCGTAACGAAGA & \\
\hline \multirow[t]{2}{*}{ GPAM } & XM_001927875.1 & F.955 & ACTATCTCCTGCTCACTITCA & 146 \\
\hline & & R.1100 & CGTCTCATCTAGCCTCCGTC & \\
\hline \multirow[t]{2}{*}{ AGPAT1 } & EU282358.1 & F.170 & CCTTCTACAACGGCTGGAT & 174 \\
\hline & & R.343 & GCTGTGAGGGAGGGAAGTGG & \\
\hline \multirow[t]{2}{*}{ AGPAT6 } & FJ439669.1 & F.56 & CTGGGCATCTCCCTGACTGT & 198 \\
\hline & & R.253 & GATTCCATTGGTGTAGGGCTTG & \\
\hline \multirow[t]{2}{*}{ DGAT1 } & AY116586.1 & F.6569 & TGGACTACTCACGCATCAT & 176 \\
\hline & & R.6744 & GTGGAAGAGCCAGTAGAAGAA & \\
\hline \multirow[t]{2}{*}{ LPIN1 } & NM_001130734.1 & F.2084 & CACATITGCCCACCCTT & 164 \\
\hline & & R.2247 & GTGCCACGCTCGTTGACC & \\
\hline \multirow[t]{2}{*}{ LPIN2 } & NM_001141987.1 & F.2026 & CCTATGGAACTGGAACGA & 141 \\
\hline & & R.2166 & TTGATGGAGTGGTAGAGCTTGG & \\
\hline \multirow[t]{2}{*}{ PLIN2 } & NM_214200.2 & F.1183 & CTCCTCAGTTCCAGCAAG & 113 \\
\hline & & R.1295 & GGATAAAAGGGACCTACCAG & \\
\hline \multirow[t]{2}{*}{ SREBP1 } & NM_214157.1 & F.984 & AGCGGACGGCTCACAATG & 121 \\
\hline & & R.1104 & CGCAAGACGGCGGATTTA & \\
\hline \multirow[t]{2}{*}{$|N S I G|$} & NM_001244521.1 & F.509 & TGTCGTGGGCTTGCTCTA & 123 \\
\hline & & R.631 & GCACTGGCGTGGTTGATG & \\
\hline \multirow[t]{2}{*}{ SCAP } & AY705448.2 & F.1089 & GCGGTGAGATTTTCCCCTAC & 185 \\
\hline & & R.1273 & GCCAATGAGGATGATGCC & \\
\hline \multirow[t]{2}{*}{ PPARa } & DQ437887.1 & F.323 & CAGCGTGGCACTGAACATC & 144 \\
\hline & & R.466 & CTCCGATCACATTTGTCATAGAC & \\
\hline \multirow[t]{2}{*}{ PPARY } & NM_214379.1 & F.1170 & AGCCCTTGGTGACTT & 213 \\
\hline & & R.1382 & AGGACTCTGGGTGGTT & \\
\hline
\end{tabular}

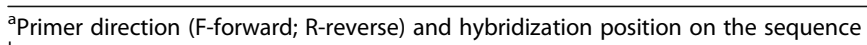

${ }^{\mathrm{b}}$ Amplicon size in base pair (bp)

\section{Statistical analysis}

Data were analyzed using General Linear Model procedure of SAS software (SAS Version 9.0) as a completely randomized design. Regression analysis was performed to evaluate linear and quadratic effects of palmitate on the various response criteria. Differences at $p<0.05$ were considered statistically significant. Values are expressed as means \pm SEM. 


\section{Results}

\section{Cell viability}

Incubation with $0 \sim 50 \mu \mathrm{M}$ palmitate for $24 \mathrm{~h}$ did not affect the viability of pMECs, but exposure to 100 600 $\mu \mathrm{M}$ palmitate decreased the cell viability by approximately $20 \%$ (Fig. 1). This indicates that cell viability tended to be suppressed when the palmitate concentration was above $50 \mu \mathrm{M}$.

\section{Accumulation of intracellular TAG}

The addition of palmitate in the medium for $24 \mathrm{~h}$ significantly increased cellular TAG contents in a dose-dependent manner (Fig. 2). Similarly, Oil Red O staining confirmed the enhanced formation of cytosolic lipid droplets in pMECs when incubated with increasing concentrations of palmitate (Fig. 3a-g). The average diameter of large lipid droplets was increased linearly or quadratically with increasing palmitate $(p<0.05)$, with the maximal value observed at 100 600 $\mu \mathrm{M}$ (Fig. 3h). These results indicate that exogenous palmitate increased cytosolic TAG accumulation and lipid droplets formation in pMECs.

\section{Upregulating the expression of genes or proteins} associated with long-chain fatty acid uptake, intracellular activation, and transport in pMECs

Incubation with $25 \sim 600 \mu \mathrm{M}$ palmitate for $24 \mathrm{~h}$ upregulated the expression of genes associated with long-chain fatty acid (LCFA) uptake ( $L P L)$, intracellular activation (ACSL3), and transport (CD36) in pMECs (Table 2). Particularly, cellular LPL and ACSL3 mRNA expression were increased linearly or quadratically with increasing

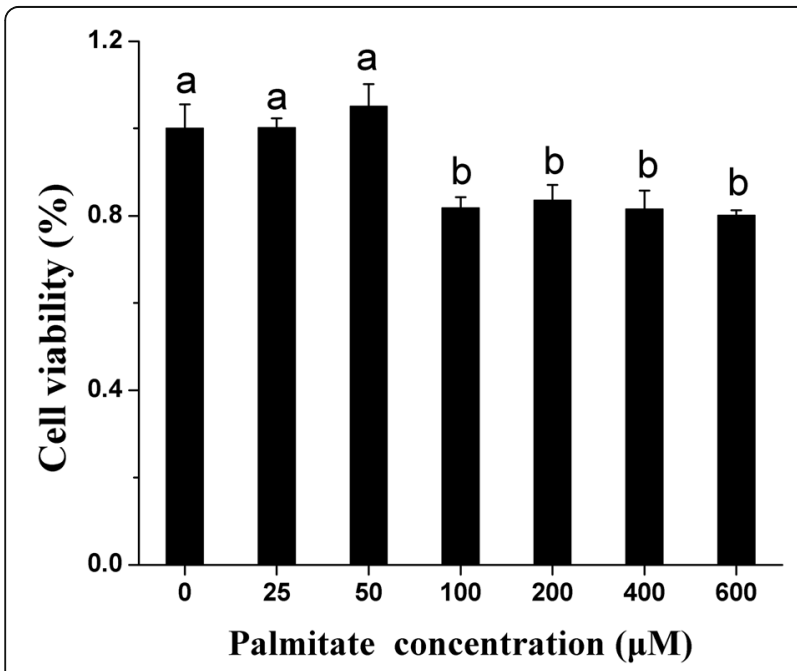

Fig. 1 Effect of palmitate on cell viability in pMECs. pMECs were incubated for $24 \mathrm{~h}$ with different concentrations of palmitate ( 0 (control), $25,50,100,200,400$, and $600 \mu \mathrm{M})$. Cell viability was estimated by MTT test. Values, expressed as percentage of control, are presented as mean \pm SEM $(n=6)$. Different letters indicate statistical significance between different concentrations of palmitate treatment groups $(p<0.05)$

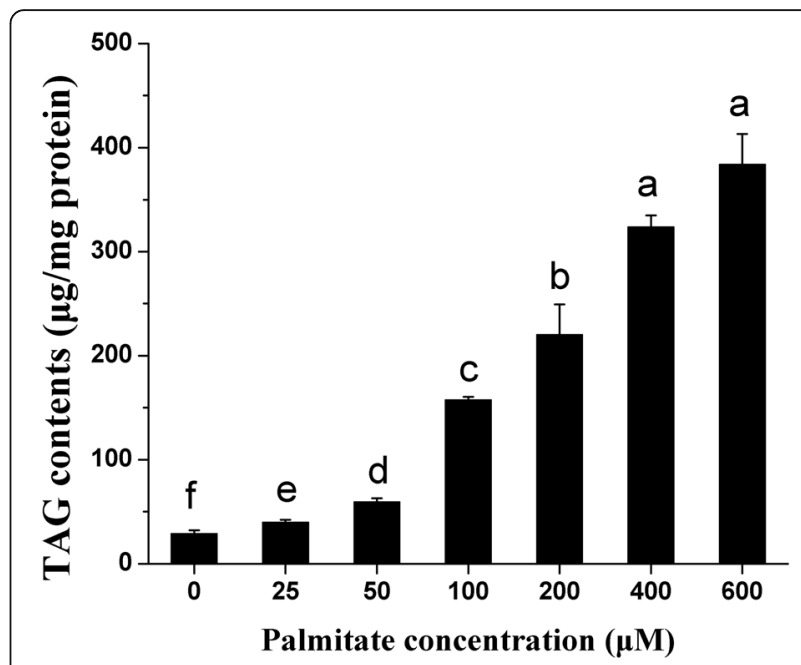

Fig. 2 Effect of palmitate on cellular TAG content in pMECs. pMECs were incubated for $24 \mathrm{~h}$ with different concentrations of palmitate (0 (control), 25, 50, 100, 200, 400, and $600 \mu \mathrm{M})$. The data are expressed as the mean \pm SEM $(n=6)$. Different letters indicate statistical significance between different concentrations of palmitate treatment groups $(p<0.05)$

palmitate $(p<0.05)$, with the maximal values observed at 200 400 $\mu \mathrm{M}$ (Table 2). CD36 and FABP3 mRNA expression in pMECs was increased linearly with increasing palmitate from 50 to $600 \mu \mathrm{M}(p<0.05)$, with the highest values at $600 \mu \mathrm{M}$ palmitate (Table 2). Consistent with its gene mRNA expression, cellular CD36 protein expression was significantly upregulated by $100 \sim 600 \mu \mathrm{M}$ palmitate $(p<0.05)$, with the highest values at $600 \mu \mathrm{M}$ palmitate (Fig. 4b).

Downregulating the expression of genes or proteins related to fatty acid de novo synthesis and desaturation in pMECs

Incubation with palmitate for $24 \mathrm{~h}$ suppressed the expression of genes associated with fatty acid de novo synthesis and desaturation in pMECs. mRNA expression of $A C A C$ $A, F A S N$, and $S C D$ in pMECs were decreased linearly or quadratically with increasing palmitate $(p<0.05$; Table 2$)$. The mRNA expression of $A C A C A$ in pMECs was downregulated by $100 \sim 600 \mu \mathrm{M}$ palmitate but not affected by 25 50 $\mu \mathrm{M}$ palmitate. Cellular mRNA abundance of FASN with $50 \sim 600 \mu \mathrm{M}$ palmitate was $45 \sim 65 \%$ lower than control. SCD mRNA expression at $100 \mu \mathrm{M}$ was $71 \%$ lower than the control (Table 2). The protein expression of ACACA in pMECs was significantly downregulated by palmitate $(p<0.05)$ (Fig. 4c).

Influencing the expression of genes or proteins related to TAG synthesis and lipid droplet formation in pMECs Incubation of pMECs with palmitate for $24 \mathrm{~h}$ increased the mRNA expression of genes associated with TAG synthesis 


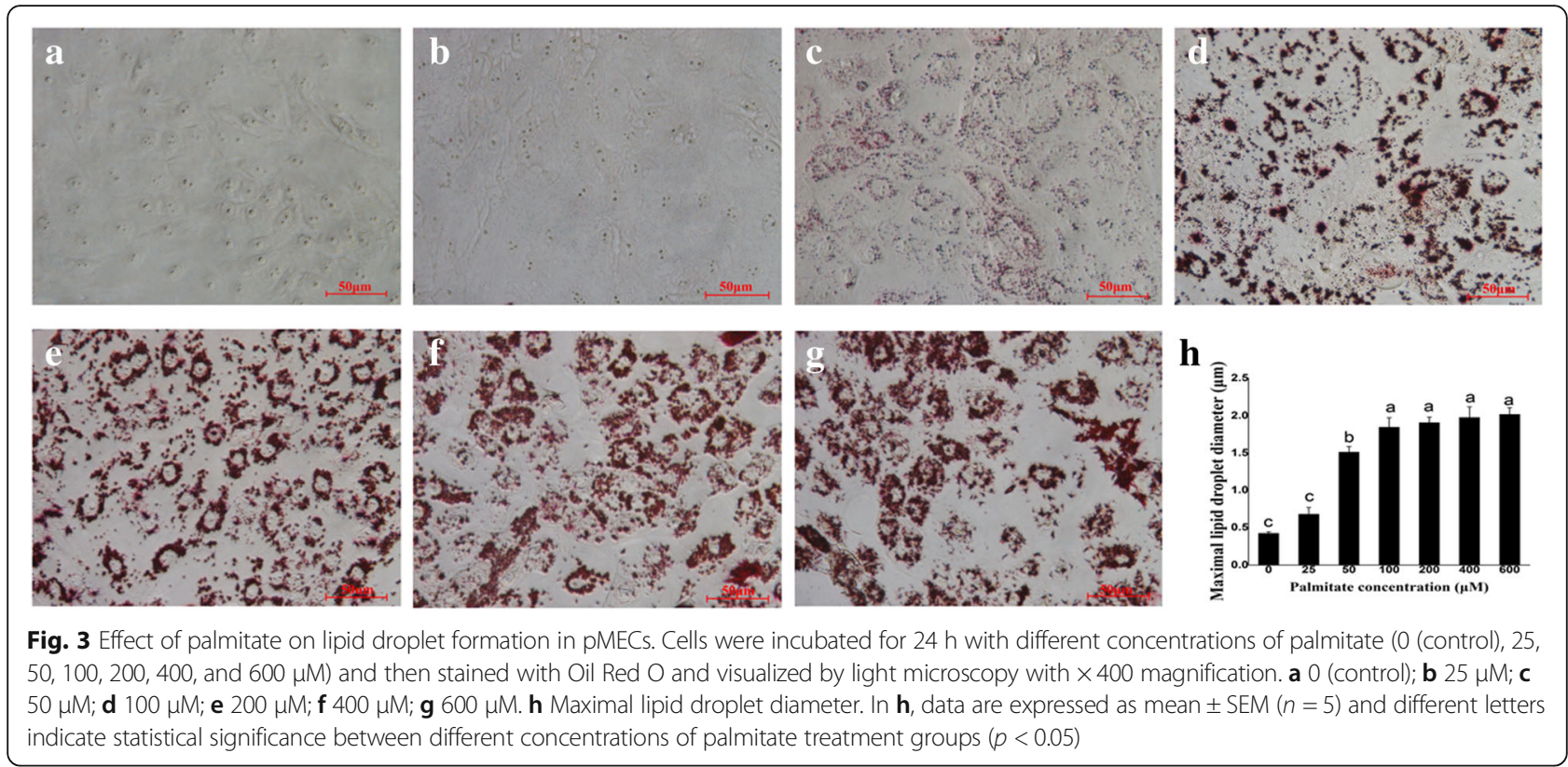

Table 2 Effect of palmitate on mRNA expression of genes involved in lipid synthesis in pMECs

\begin{tabular}{|c|c|c|c|c|c|c|c|c|c|c|c|}
\hline \multirow[t]{2}{*}{ Gene } & \multicolumn{7}{|c|}{ Palmitate concentration $(\mu \mathrm{M})$} & \multirow[t]{2}{*}{ SEM } & \multicolumn{3}{|l|}{$P$ value } \\
\hline & 0 & 25 & 50 & 100 & 200 & 400 & 600 & & Palmitate & Linear & Quadratic \\
\hline \multicolumn{12}{|c|}{ Fatty acid uptake and import into cells } \\
\hline CD36 & $1.00^{\mathrm{d}}$ & $2.11^{\mathrm{cd}}$ & $2.63^{b c}$ & $1.91^{\mathrm{cd}}$ & $2.48^{\mathrm{bc}}$ & $3.49^{\mathrm{b}}$ & $4.73^{\mathrm{a}}$ & 0.14 & $<0.001$ & $<0.0001$ & 0.10 \\
\hline$L P L$ & $1.00^{c}$ & $1.96^{\mathrm{bc}}$ & $2.47^{\mathrm{abc}}$ & $2.32^{\mathrm{abc}}$ & $3.74^{\mathrm{a}}$ & $2.67^{\mathrm{ab}}$ & $2.17^{\mathrm{bc}}$ & 0.17 & 0.03 & 0.02 & 0.01 \\
\hline \multicolumn{12}{|c|}{ Fatty acid activation and intra-cellular transport } \\
\hline ACSL3 & $1.00^{\mathrm{e}}$ & $1.44^{\mathrm{d}}$ & $1.75^{\mathrm{cd}}$ & $1.98^{\mathrm{bc}}$ & $1.97^{\mathrm{bc}}$ & $2.58^{\mathrm{a}}$ & $2.19^{b}$ & 0.05 & $<0.0001$ & 0.0001 & 0.02 \\
\hline$F A B P 3$ & $1.00^{\mathrm{d}}$ & $1.17^{d}$ & $1.73^{c}$ & $2.36^{\mathrm{b}}$ & $2.05^{\mathrm{bc}}$ & $2.35^{\mathrm{b}}$ & $3.50^{\mathrm{a}}$ & 0.06 & $<0.0001$ & $<0.0001$ & 0.26 \\
\hline \multicolumn{12}{|c|}{ Fatty acid de novo synthesis and desaturation } \\
\hline ACACA & $1.00^{\mathrm{a}}$ & $1.15^{\mathrm{a}}$ & $1.01^{\mathrm{a}}$ & $0.48^{b}$ & $0.52^{\mathrm{b}}$ & $0.65^{\mathrm{b}}$ & $0.52^{b}$ & 0.04 & $<0.001$ & $<0.0001$ & 0.22 \\
\hline FASN & $1.00^{\mathrm{a}}$ & $0.96^{\mathrm{a}}$ & $0.53^{b}$ & $0.52^{\mathrm{b}}$ & $0.43^{b}$ & $0.46^{\mathrm{b}}$ & $0.34^{\mathrm{b}}$ & 0.03 & $<0.0001$ & $<0.0001$ & $<0.01$ \\
\hline$S C D$ & $1.00^{\mathrm{ab}}$ & $0.64^{\mathrm{abc}}$ & $0.34^{\text {cd }}$ & $0.27^{d}$ & $0.55^{\mathrm{bcd}}$ & $0.55^{\mathrm{bcd}}$ & $1.13^{\mathrm{a}}$ & 0.06 & 0.01 & 0.62 & $<0.001$ \\
\hline \multicolumn{12}{|c|}{ TAG synthesis and lipid droplet formation } \\
\hline AGPAT1 & 1.00 & 1.21 & 1.16 & 1.03 & 1.16 & 1.51 & 1.41 & 0.05 & 0.11 & 0.02 & 0.42 \\
\hline AGPAT6 & $1.00^{c}$ & $1.50^{b}$ & $1.34^{\mathrm{bc}}$ & $1.37^{\mathrm{bc}}$ & $1.39^{\mathrm{bc}}$ & $2.25^{\mathrm{a}}$ & $2.13^{\mathrm{a}}$ & 0.06 & $<0.01$ & $<0.0001$ & 0.21 \\
\hline LPIN1 & $1.00^{\mathrm{ab}}$ & $0.85^{b c}$ & $0.69^{b c}$ & $0.80^{\mathrm{bc}}$ & $0.48^{\mathrm{C}}$ & $1.31^{\mathrm{a}}$ & $0.75^{b c}$ & 0.05 & 0.03 & 0.94 & 0.14 \\
\hline LPIN2 & $1.00^{\mathrm{b}}$ & $1.08^{b}$ & $0.84^{\mathrm{bc}}$ & $0.94^{\mathrm{bc}}$ & $0.70^{c}$ & $1.93^{\mathrm{a}}$ & $2.10^{\mathrm{a}}$ & 0.04 & $<0.0001$ & $<0.0001$ & $<0.0001$ \\
\hline DGAT1 & $1.00^{\mathrm{d}}$ & $1.80^{c}$ & $1.80^{c}$ & $1.61^{c}$ & $2.56^{\mathrm{b}}$ & $2.17^{\mathrm{bc}}$ & $3.28^{\mathrm{a}}$ & 0.07 & $<0.0001$ & $<0.0001$ & 0.27 \\
\hline GPAM & $1.00^{\mathrm{b}}$ & $1.25^{\mathrm{b}}$ & $1.49^{b}$ & $1.57^{\mathrm{b}}$ & $1.57^{\mathrm{b}}$ & $2.81^{\mathrm{a}}$ & $2.42^{\mathrm{a}}$ & 0.10 & $<0.01$ & $<0.0001$ & 0.50 \\
\hline PLIN2 & $1.00^{c}$ & $0.90^{c}$ & $1.48^{c}$ & $1.55^{\mathrm{c}}$ & $2.70^{\mathrm{b}}$ & $3.37^{b}$ & $5.52^{\mathrm{a}}$ & 0.18 & $<0.0001$ & $<0.0001$ & $<0.01$ \\
\hline \multicolumn{12}{|c|}{ Regulation of transcription } \\
\hline SREBP1 & $1.00^{\mathrm{ab}}$ & $1.03^{\mathrm{a}}$ & $0.61^{c}$ & $0.68^{c}$ & $0.66^{c}$ & $0.76^{b c}$ & $0.53^{\mathrm{c}}$ & 0.03 & $<0.01$ & $<0.001$ & 0.16 \\
\hline PPARa & 1.00 & 1.12 & 0.90 & 1.11 & 0.92 & 0.87 & 1.02 & 0.05 & 0.78 & 0.57 & 0.89 \\
\hline PPARY & $1.00^{c}$ & $2.03^{b c}$ & $1.80^{\mathrm{bc}}$ & $0.91^{c}$ & $1.73^{b c}$ & $2.83^{\mathrm{ab}}$ & $4.73^{\mathrm{a}}$ & 0.27 & 0.03 & $<0.01$ & 0.05 \\
\hline INSIGI & $1.00^{\mathrm{abc}}$ & $1.06^{\mathrm{abc}}$ & $0.84^{b c d}$ & $0.73^{\mathrm{cd}}$ & $0.52^{d}$ & $1.21^{\mathrm{ab}}$ & $1.38^{\mathrm{a}}$ & 0.05 & $<0.01$ & 0.10 & $<0.001$ \\
\hline SCAP & $1.00^{c}$ & $1.43^{\mathrm{a}}$ & $1.21^{\mathrm{b}}$ & $1.03^{c}$ & $0.98^{c}$ & $1.40^{\mathrm{a}}$ & $1.20^{\mathrm{b}}$ & 0.02 & $<0.0001$ & 0.29 & 0.49 \\
\hline
\end{tabular}




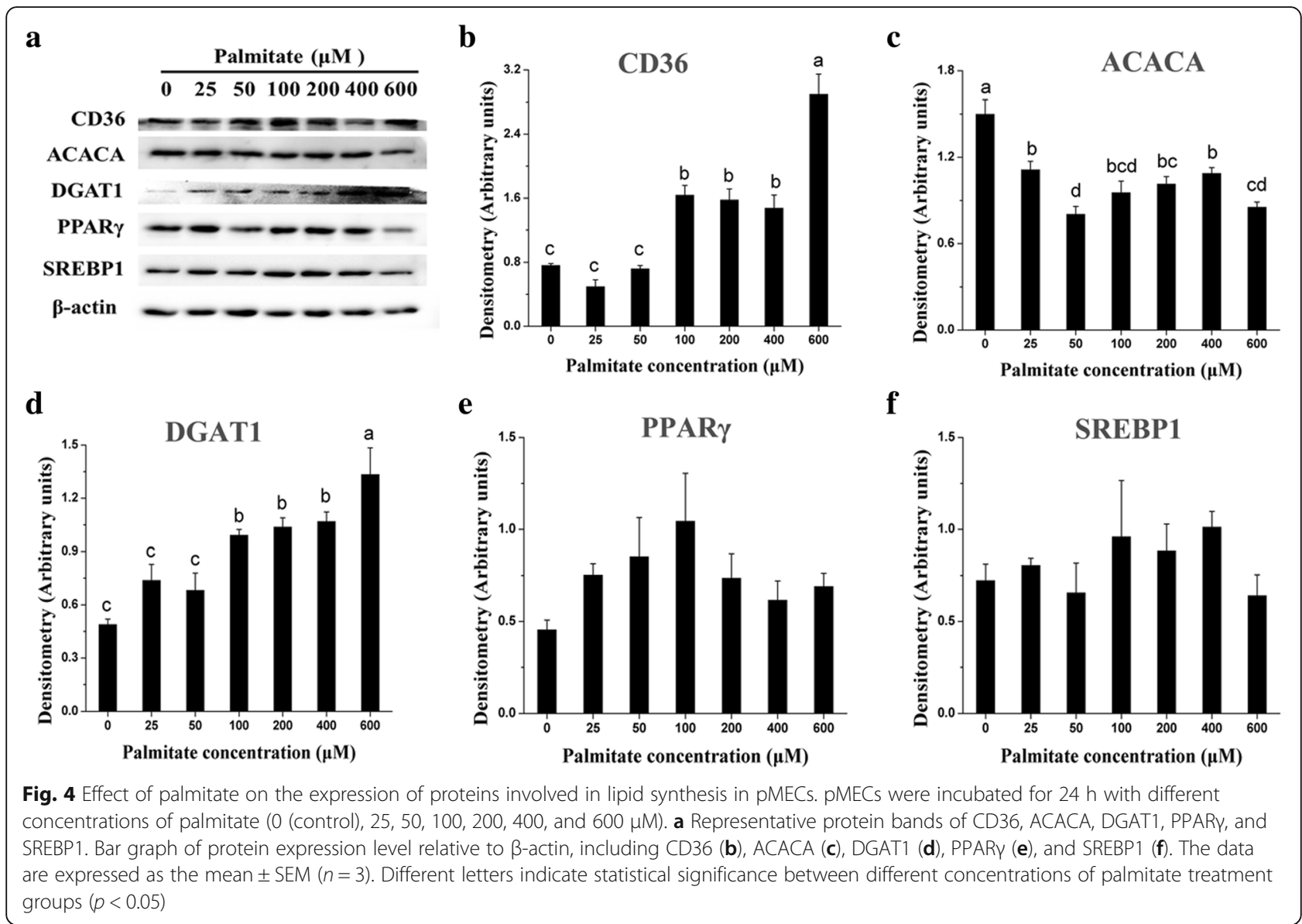

(GPAM, AGPAT6, DGAT1) and lipid droplet formation (PLIN2) (Table 2). The cellular mRNA expression of GPAM, AGPAT6, DGAT1, and PLIN2 were increased linearly or quadratically with increasing palmitate $(p<0.05$; Table 2). Similarly, the DGAT1 protein expression in pMECs was significantly upregulated by 100 600 $\mu \mathrm{M}$ palmitate $(p<0.05)$, with the highest values observed at $600 \mu \mathrm{M}$ palmitate (Fig. 4d).

Influencing the expression of genes or proteins related to regulation of transcription in pMECs

$P P A R \gamma$ mRNA expression in pMECs was increased linearly or quadratically with increasing palmitate $(p<0.05)$, with maximal values observed at $600 \mu \mathrm{M}$. In contrast to $P P A R \gamma$, the mRNA expression of SREBP1 and INSIG1 were decreased linearly or quadratically with increasing palmitate $(p<0.05$; Table 2$)$, with minimum values observed at 600 or $200 \mu \mathrm{M}$ palmitate, respectively. SCAP mRNA expression in pMECs was increased by $25 \sim 50 \mu \mathrm{M}$ or 400 600 $\mu \mathrm{M}$ palmitate but decreased by $100 \sim 200 \mu \mathrm{M}$ palmitate $(p<0.05)$. The cellular PPAR $\alpha$ mRNA expression was not affected by palmitate. The protein expressions of PPARY and SREBP1 in pMECs were not affected by palmitate (Fig. $4 \mathrm{e}, \mathrm{f}$ ).

\section{Discussion}

In this study, we found that $\leq 50 \mu \mathrm{M}$ palmitate did not affect the viability of pMECs (Fig. 1), but higher concentrations $(\geq 100 \mu \mathrm{M})$ of palmitate decreased the cell viability. It was evident that the optimal concentration of palmitate for pMECs viability ranged from $0 \sim 50 \mu \mathrm{M}$. Similar to our results, it was reported in bovine mammary epithelial cells (bMECs) that cell proliferation tended to be suppressed when palmitate was above $100 \mu \mathrm{M}$ [14]. Although the reason for suppression of cell viability with high concentrations of palmitate has not been elucidated in this study, the mechanism by which palmitate causes cell death has been reported in other types of cells to be related to oxidative injury [15-17].

In the current study, we also found that the addition of exogenous palmitate to pMECs increased cytosolic TAG contents in a concentration-dependent manner and enhanced the formation of lipid droplets. It was notable that the high concentration of palmitate enhanced lipid synthesis even when the cell viability was suppressed. Consistent with our results, it was reported that addition of 200 600 $\mu \mathrm{M}$ palmitate to bMECs enhanced the accumulation of cellular TAG [16, 18-20]. TAG and other neutral lipids are stored in cytoplasmic 
lipid droplets, the immediate precursors of milk lipids [21]. We observed that the larger droplets in the palmitate treatment were associated with higher cellular TAG content in pMECs.

We also evaluated the promotive effect of palmitate on TAG synthesis and potential mediation through regulation of lipid synthesis-related pathways, including fatty acid de novo synthesis and uptake of exogenous fatty acid. It is known that mammary cells take up LCFA from albumin-bound fatty acids and lipoproteins, and this process is dependent on membrane hydrolase and fatty acid transport proteins. The enzyme LPL is located in the capillary lumen in the mammary gland and functions to hydrolyze circulation-derived TAG into free fatty acids. Subsequently, the free fatty acids are transported into cells by transport proteins. CD36 is the main protein responsible for exogenous LCFA trans-membrane transport in lactating mammary glands [2, 22, 23]. Our previous study demonstrated that both $L P L$ and CD36 have higher mRNA expression as early as the onset of milk synthesis in the lactating porcine mammary gland [2]. In this study, we observed that exogenous palmitate enhanced the expression of LPL mRNA in pMECs (Table 2), although it has been reported that LPL mRNA expression in bMECs is not affected by addition of palmitate [24]. Similarly, palmitate enhanced cellular CD36 expression at both the mRNA and protein level (Fig. 4b). Consistent with our results, it was reported that palmitate increased the cellular CD36 mRNA expression in bMECs $[18,20]$. Our results, and reports in the literature, indicate that provision of exogenous palmitate to mammary epithelial cells can activate intracellular LCFA uptake.

LCFA is activated by ACSL to bind an acyl coenzyme A (CoA) before it is used to synthesize TAG. FABP facilitates the cytosolic transport of both long-chain saturated and unsaturated fatty acids. We previously found that ACSL3 and FABP3 were the major isoforms within each gene family in lactating porcine mammary tissue, and their mRNA abundance was upregulated during lactation [2]. In the current study, the mRNA expressions of $A C S L 3$ and FABP3 in pMECs were increased linearly or quadratically with increasing concentration of palmitate added $(25 \sim 600 \mu \mathrm{M})$. These results are in accordance with previous reports showing that exposure of bMECs to palmitate enhanced the cellular expression of $F A B P 3$ [24]. However, another independent in vitro study showed that FABP3 mRNA expression in bMECs was inhibited by addition of palmitate in the culture medium [20]. Elucidation of the reasons for inconsistent regulation of FABP3 in bMECs and pMECs by palmitate will require additional research. Our results suggest that palmitate exerts a positive effect on LCFA uptake ( $L P L$ and CD36), fatty acid activation (ACSL3), and intracellular transport (FABP3).
FASN and ACACA are considered the crucial enzymes of cellular fatty acid de novo synthesis in the mammary gland, which have been reported to be the primary source of short- and medium-chain fatty acids (almost all C4:0 C14:0 and approximately 50\% of palmitic acid) of milk $[25,26]$. In this study, the fatty acid de novo synthesis in pMECs was suppressed by $50 \sim 600 \mu \mathrm{M}$ palmitate, as reflected by the downregulated genes for $A C A C$ $A$ and $F A S N$. This is in agreement with previous work in bMECs showing that palmitate suppressed fatty acid de novo synthesis [20]. Suppressive hepatic de novo lipogenesis was also observed in high-fat diet-fed mice [27]. Similarly, it was reported that, in in vivo studies, dietary supplementation of palmitic acid to dairy cows decreased the concentrations of milk de novo synthesized fatty acids (C6:0 C14:0) probably through suppressing the expression of $A C A C A$ and FASN [28-30]. Our results indicated that the fatty acid de novo synthesis in pMECs was suppressed by a higher concentration of exogenous palmitate. The suppressed expression of genes related to fatty acid de novo synthesis was probably due to the palmitate-induced downregulated upstream regulator (SREBP1). However, the reduced cell viability by palmitate at a higher concentration may contribute, to some extent, to the suppression of fatty acid de novo synthesis especially when cells are exposed to $\geq 100 \mu \mathrm{M}$ palmitate. We also found that palmitate addition suppressed desaturation of LCFA in pMECs, as reflected by the downregulated mRNA expression of $S C D$, the key enzyme responsible for inducing the double bond at $\Delta^{9}$ location of saturated fatty acids [31].

The ultimate synthesis of TAG involves the transfer of acyl-fatty acid to the activated glycerol backbone, the process of which is facilitated by acyltransferases, including glycerol-3-phosphate acyltransferase (GPAM), 1-acylglycerol-3-phosphate O-acyltransferases (AGPAT), and diacylglycerol O-acyltransferase (DGAT1) [32]. Additionally, LPIN1 encodes a phosphohydrolase enzyme that catalyzes the dephosphorylation of phosphatidic acid to yield diacylglycerol. PLIN2 (adipophilin) is located on the droplet surface and is associated with lipid droplet storage and control of cellular lipolytic activity [33, 34]. The transcripts of AGPAT1, LPIN1/2, DGAT1, and PLIN2 are the most abundant transcripts within each specific gene family in the lactating porcine mammary gland [2]. In this study, the mRNA expressions of genes associated with TAG synthesis (GPAM, AGPAT1/6, LPIN2, DGAT1) and lipid droplet formation (PLIN2) in pMECs were upregulated or tended to be upregulated by palmitate, which is consistent with the promotive effect of palmitate on cellular TAG synthesis and lipid droplets formation. Similar results have been reported by Kadegowda et al. [24] in bMECs.

It has been shown in previous studies that sterol regulatory element binding protein-1 (SREBP1) and PPAR $\gamma$ are 
of importance in transcriptional regulation of many genes related to milk fat synthesis and secretion and therefore control fatty acid synthesis and uptake in mammary cells [24, 35-38]. In this study, palmitate increased $P P A R \gamma$ mRNA expression in pMECs. This indicates that palmitate regulates TAG synthesis probably through activating $P P A R Y$ and target lipogenic genes, since most LCFAs, including palmitate, are natural ligands and bind to PPAR $\gamma$ and therefore can modulate gene expression and rates of lipogenesis $[39,40]$. A recent in vitro study in a liver cell line showed that palmitate modulated the expression of miR-122 and miR-370, which are involved in lipogenesis [41]. This report revealed a new molecular mechanism mediating palmitate-induced TAG synthesis. However, we found that palmitate decreased the cellular mRNA expression of SREBP1 in pMECs, which is in accordance with a report showing that $100 \mu \mathrm{M}$ LCFA downregulated the expression of SREBP1 in bMECs [24]. Our results indicate that palmitate suppresses fatty acid de novo synthesis-related genes ( $A C A C A$ and $F A S N$ ) probably via SREBP1 regulation. SREBP1 has been reported as a key regulator for upregulating genes that encode proteins (ACACA and FASN) involved in fatty acid de novo synthesis in mammary epithelial cells [38].

It can be assumed that the mammary epithelial cells prefer to synthesize milk lipids through uptake of exogenous

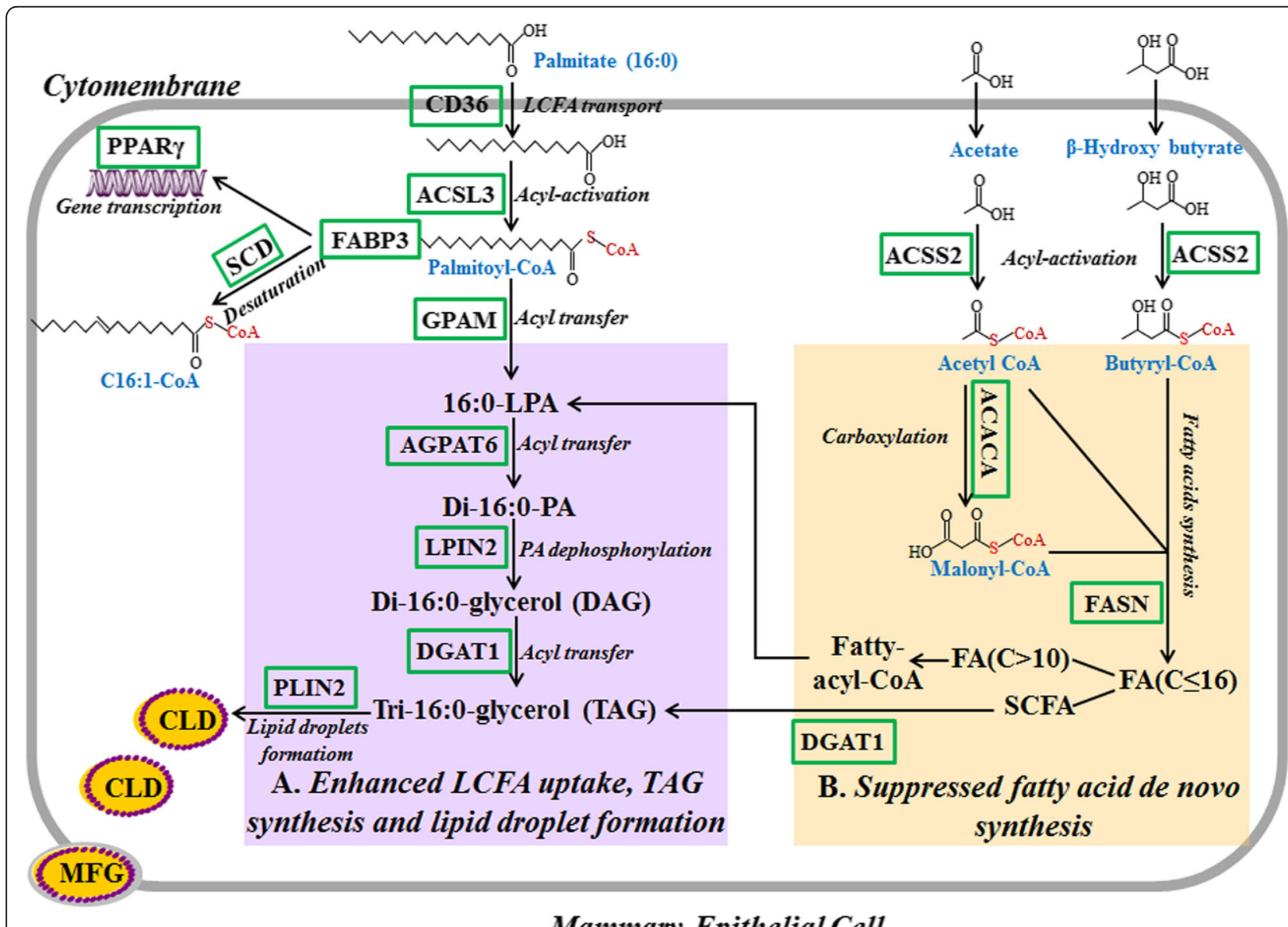

\section{Mammary Epithelial Cell}

Fig. 5 Scheme summarizing interrelationships among cellular pathways regulating lipid synthesis by palmitate in pMECs. a Palmitate enhanced the uptake of exogenous LCFA, TAG synthesis, and lipid droplet formation. Uptake of LCFA in pMECs, exampled by palmitate (16:0), was enhanced by palmitate through activating transport proteins (mainly CD36). Cytosolic 16:0 is converted into its activated form (16:0-CoA), with the help of ACSL. Cytosolic 16:0-CoA is transported to endoplasmic reticulum membrane by FABP and esterified there to glycerol-3-phosphate to produce 16:0-LPA by GPAM. In endoplasmic reticulum, addition of a second 16:0-CoA produces di-16:0-PA; di-16:0-PA can be hydrolyzed with LPIN to form a di-16:0-glycerol (DAG). The sn-3 position of DAG is then acylated to form TAG by DGAT. Newly formed TAG forms cytoplasmic lipid droplet in the ER membrane via incorporation. Then, the cytoplasmic lipid droplet was transported to the apical membrane and eventually released. b Palmitate suppressed the fatty acid de novo synthesis. In mammary cell, short- and medium-chain fatty acids (almost all C4:0 C14:0 and approximately $50 \%$ of palmitic acid) were highly dependent on the de novo synthesis. A series of cytosolic enzymes are required to facilitate this process, of which FASN and ACACA are considered the crucial enzymes of cellular fatty acid de novo synthesis in the porcine mammary gland. ACACA carboxylates acetyl-COA to form malonyl-CoA, which is further converted by FASN to fatty acids (C $\leq 16)$. Then, the synthesized fatty acids participate in the TAG formation in endoplasmic reticulum 
LCFA rather than through de novo fatty acid synthesis provided that cells have access to abundant palmitate. This assumption was supported by a recent study showing that proliferating fibroblasts prefer to take up palmitate from the extracellular environment rather than synthesizing it de novo [42]. A previous in vivo study showed that feeding high-fat diets promoted hepatic lipid accumulation in mice, and this effect was mainly due to an increased hepatic elongation of palmitate rather than to elongation of de novo synthesized palmitate [43]. Another independent study also demonstrated that, in high-fat diet-fed mice, most hepatic TAG was formed from the re-esterification of existing or ingested lipids but not de novo lipogenesis [27]. Based on our results, we concluded that when exogenous palmitate is provided in the culture media at physiological concentrations, the uptake of extracellular LCFA plays a major role in enhanced TAG synthesis and lipid formation in pMECs, while fatty acid de novo synthesis accounts for a minor fraction of intracellular TAG.

\section{Implication}

Milk fat is an important component of sow milk and provides a large proportion of both calories and essential fatty acids (EFAs) required for the newborn [44]. The lactating porcine mammary gland is estimated to produce approximately $8 \mathrm{~kg}$ of milk containing $5 \%$ fat per day [3]. Since TAG accounts for $>90 \%$ of milk fat, the mammary gland synthesizes about $400 \mathrm{~g}$ of TAG daily or nearly $8.4 \mathrm{~kg}$ fat during 21 days of lactation. Because modern sows have lower feed intake during lactation, the dietary energy source should be formulated to support this high level of milk fat production [45], prevent sow's tissue mobilization, and maximize long-term productivity. Given that mammary epithelial cells prefer exogenous LCFA to synthesize TAG, the dietary addition of optimal amounts of fat to support lipid synthesis from two origins may represent the most efficient way for promoting milk fat synthesis. In practical production, addition of 3 5\% fat to the sow's lactation diet can actually increase fat and energy output in sow milk and improve growth performance of nursing piglets [46-48]. Of course, the form of fatty acids (e.g., saturated or unsaturated, number of carbon) should also be considered in practical production.

\section{Conclusions}

In summary, our results indicate that palmitate enhanced the cytosolic TAG accumulation in a dose-dependent manner. This is probably because palmitate can regulate the channeling of fatty acids towards milk TAG synthesis and secretion in pMECs though activating the PPAR $\gamma$ pathway and upregulating the target genes associated with milk fat biosynthesis, including LPL and CD36 (LCFA uptake); ACSL3 and FABP3 (intracellular activation and transport); GPAM, AGPAT6, and DGAT1 (TAG synthesis); and PLIN2 (lipid droplet formation) (Fig. 5a). Furthermore, palmitate treatment inhibits milk fatty acid de novo synthesis through suppressing ACACA and FASN gene (fatty acid de novo synthesis) expression (Fig. 5b).

\begin{abstract}
Abbreviations
ACACA: Acetyl-CoA carboxylase 1; ACSL3: Acyl-CoA synthetase long-chain family member 3; ACSS2: Acyl-CoA synthetase short-chain family member 2; AGPAT1/6: 1-Acylglycerol-3-phosphate O-acyltransferase 1/6; bMECs: Bovine mammary epithelial cells; CD36: Fatty acid translocase/CD36; CLD: Cytoplasmic lipid droplet; DAG: Diacylglycerol; DGAT1: Diacylglycerol acyltransferase 1; FABP3: Fatty acid binding protein 3; FASN: Fatty acid synthase; GPAM: Glycerol-3phosphate acyltransferase, mitochondrial; HSL: Hormone-sensitive lipase; INSIG1: Insulin-induced gene 1; LCFA: Long-chain fatty acid; LPA: Lysophosphatidic acid; LPIN1/2: Lipin 1/2; LPL: Lipoprotein lipase; MFG: Milk fat globule; PA: Phosphatidic acid; PLIN2: Perilipin 2; pMECs: Porcine mammary epithelial cells; PPARa/Y: Peroxisome proliferator-activated receptor alpha/ gamma; PUFA: Polyunsaturated fatty acids; SCAP: Sterol response element binding protein cleavage-activating protein; SCD: Stearoyl-CoA desaturase; SCFA: Short-chain fatty acid; SREBP1: Sterol regulatory element binding protein 1; TAG: Triacylglycerol
\end{abstract}

\section{Acknowledgements}

The authors thank Dr. Y.Z. Chen and his colleagues from the Animal Hospital of South China Agricultural University for technical assistance with the biopsies. The authors also thank Dr. W. Chen for his help in the presentation of this manuscript.

\section{Funding}

This study was supported by the National Key R\&D Program of China (No. 2017YFD0500501).

\section{Availability of data and materials}

The datasets used and/or analyzed during the current study are available from the corresponding author on reasonable request.

\section{Authors' contributions}

LY and GW designed the study. LY, ZS, and CF conducted the statistical analysis. LY, ZY, CJ, and LY performed the experiments. LY and GW wrote the paper. All authors read and approved the final manuscript.

\section{Ethics approval}

This article does not contain any studies with human or animal subjects performed by any of the authors.

Consent for publication

Not applicable.

\section{Competing interests}

The authors declare that they have no competing interests.

\section{Author details}

'Guangdong Provincial Key Laboratory of Animal Nutrition Control, College of Animal Science, South China Agricultural University, Guangzhou 510642, People's Republic of China. ${ }^{2}$ College of Animal Science and National Engineering Research Center for Breeding Swine Industry, South China Agricultural University, Guangzhou 510642, People's Republic of China.

${ }^{3}$ Agro-Biological Gene Research Center, Guangdong Academy of Agricultural Sciences, Guangzhou 510640, People's Republic of China.

Received: 27 March 2018 Accepted: 8 June 2018

Published online: 06 July 2018

\section{References}

1. Innis SM. Dietary triacylglycerol structure and its role in infant nutrition. Adv Nutr. 2011;2:275-83.

2. LV Y, Guan W, Qiao H, Wang C, Chen F, Zhang Y, Liao Z. Veterinary medicine and omics (veterinomics): metabolic transition of milk 
triacylglycerol synthesis in sows from late pregnancy to lactation. OMICS. 2015;19:602-16.

3. Laws J, Amusquivar E, Laws A, Herrera E, Lean IJ, Dodds PF, Clarke L. Supplementation of sow diets with oil during gestation: sow body condition, milk yield and milk composition. Livest Sci. 2009;123:88-96.

4. Novak EM, Innis SM. Impact of maternal dietary $n-3$ and $n-6$ fatty acids on milk medium-chain fatty acids and the implications for neonatal liver metabolism. Am J Physiol Endocrinol Metab. 2011;301:E807-17.

5. Innis SM, Dyer R, Quinlan P, Diersen-Schade D. Palmitic acid is absorbed as sn-2 monopalmitin from milk and formula with rearranged triacylglycerols and results in increased plasma triglyceride sn-2 and cholesteryl ester palmitate in piglets. J Nutr. 1995;125:73-81.

6. Straarup EM, Lauritzen L, Faerk J, Høy CE (Deceased), Michaelsen KF. The stereospecific triacylglycerol structures and fatty acid profiles of human milk and infant formulas. J Pediatr Gastroenterol Nutr 2006:42:293-299.

7. Scow RO, Chernick SS, Fleck TR. Lipoprotein lipase and uptake of triacylglycerol, cholesterol and phosphatidyl choline from chylomicrons by mammary and adipose tissue of lactating rats in vivo. Biochim Biophys Acta. 1977;487:297-306

8. Lauridsen C, Danielsen V. Lactational dietary fat levels and sources influence milk composition and performance of sows and their progeny. Livest Prod Sci. 2004;91:95-105.

9. Smith S, Gagné HT, Pitelka DR, Abraham S. The effect of dietary fat on lipogenesis in mammary gland and liver from lactating and virgin mice. Biochem J. 1969;115:807-15.

10. Rudolph MC, McManaman JL, Phang T, Russell T, Kominsky DJ, Serkova NJ, Stein T, Anderson SM, Neville MC. Metabolic regulation in the lactating mammary gland: a lipid synthesizing machine. Physiol Genomics. 2007;28:323-36.

11. Rudolph MC, Monks J, Burns V, Phistry M, Marians R, Foote MR, Bauman DE, Anderson SM, Neville MC. Sterol regulatory element binding protein and dietary lipid regulation of fatty acid synthesis in the mammary epithelium. Am J Physiol Endocrinol Metab. 2010;299:E918-27.

12. Zheng YM, He XY. Characteristics and EGFP expression of porcine mammary gland epithelial cells. Res Vet Sci. 2010;89:383-90.

13. Livak KJ, Schmittgen TD. Analysis of relative gene expression data using realtime quantitative PCR and the 2- $\Delta \Delta C \mathrm{Ct}$ method. Methods. 2001;25:402-8,

14. Yonezawa T, Sanosaka M, Haga S, Kobayashi Y, Katoh K, Obara Y. Regulation of uncoupling protein 2 expression by long-chain fatty acids and hormones in bovine mammary epithelial cells. Biochem Biophys Res Commun. 2008; 375:280-5.

15. Hardy S, El-Assaad W, Przybytkowski E, Joly E, Prentki M, Langelier Y. Saturated fatty acid-induced apoptosis in MDA-MB-231 breast cancer cells. A role for cardiolipin. J Biol Chem. 2003;278:31861-70.

16. Cohen BC, Shamay A, Argov-Argaman N. Regulation of lipid droplet size in mammary epithelial cells by remodeling of membrane lipid composition-a potential mechanism. PLoS One. 2015;10:e0121645.

17. Liu J, Chang F, Li F, Fu H, Wang J, Zhang S, Zhao J, Yin D. Palmitate promotes autophagy and apoptosis through ROS-dependent JNK and p38 MAPK. Biochem Biophys Res Commun. 2015;463:262-7.

18. Yonezawa T, Yonekura S, Kobayashi Y, Hagino A, Katoh K, Obara Y. Effects of long-chain fatty acids on cytosolic triacylglycerol accumulation and lipid droplet formation in primary cultured bovine mammary epithelial cells. J Dairy Sci. 2004;87:2527-34

19. Yonezawa T, Haga S, Kobayashi Y, Katoh K, Obara Y. Unsaturated fatty acids promote proliferation via ERK1/2 and Akt pathway in bovine mammary epithelial cells. Biochem Biophys Res Commun. 2008;367:729-35.

20. Qi L, Yan S, Sheng R, Zhao Y, Guo X. Effects of saturated long-chain fatty acid on mRNA expression of genes associated with milk fat and protein biosynthesis in bovine mammary epithelial cells. Asian Australas J Anim Sci. 2014;27:414-21.

21. McManaman JL. Formation of milk lipids: a molecular perspective. Clin Lipidol. 2009;4:391-401.

22. Bionaz $\mathrm{M}$, Loor JJ. Gene networks driving bovine milk fat synthesis during the lactation cycle. BMC Genomics. 2008:9:366.

23. Mohammad MA, Haymond MW. Regulation of lipid synthesis genes and milk fat production in human mammary epithelial cells during secretory activation. Am J Physiol Endocrinol Metab. 2013;305:E700-16.

24. Kadegowda AKG, Bionaz M, Piperova LS, Erdman RA, Loor JJ. Peroxisome proliferator-activated receptor- $\gamma$ activation and long-chain fatty acids alter lipogenic gene networks in bovine mammary epithelial cells to various extents. J Dairy Sci. 2009;92:4276-89.
25. Bauman DE, Griinari JM. Nutritional regulation of milk fat synthesis. Annu Rev Nutr. 2003;23:203-27.

26. Bauman DE, Harvatine KJ, Lock AL. Nutrigenomics, rumen-derived bioactive fatty acids, and the regulation of milk fat synthesis. Annu Rev Nutr. 2011;31: 299-319.

27. Duarte JA, Carvalho F, Pearson M, Horton JD, Browning JD, Jones JG, Burgess SC. A high-fat diet suppresses de novo lipogenesis and desaturation but not elongation and triglyceride synthesis in mice. J Lipid Res. 2014;55(12):2541-53.

28. Nobles RC, Steele W, Moore JH. The effects of dietary palmitic and stearic acids on milk fat composition in the cow. J Dairy Res. 1969;36:375-81.

29. Wright TC, Cant JP, McBride BW. Inhibition of fatty acid synthesis in bovine mammary homogenate by palmitic acid is not a detergent effect. J Dairy Sci. 2002;85:642-7.

30. Warntjes JL, Robinson PH, Galo E, DePeters EJ, Howes D. Effects of feeding supplemental palmitic acid (C16:0) on performance and milk fatty acid profile of lactating dairy cows under summer heat. Anim Feed Sci Tech. 2008;140:241-57.

31. Conte G, Mele M, Chessa S, Castiglioni B, Serra A, Pagnacco G, Secchiari P. Diacylglycerol acyltransferase 1, stearoyl-CoA desaturase 1, and sterol regulatory element binding protein 1 gene polymorphisms and milk fatty acid composition in Italian Brown cattle. J Dairy Sci. 2010;93:753-63.

32. Tracey TJ, Steyn FJ, Wolvetang EJ, Ngo ST. Neuronal lipid metabolism: multiple pathways driving functional outcomes in health and disease. Front Mol Neurosci. 2018:11:10

33. Brasaemle DL. Thematic review series: adipocyte biology. The perilipin family of structural lipid droplet proteins: stabilization of lipid droplets and control of lipolysis. J Lipid Res. 2007;48:2547-59.

34. Kaushik S, Cuervo AM. Degradation of lipid droplet-associated proteins by chaperone-mediated autophagy facilitates lipolysis. Nat Cell Biol. 2015;17:759-70.

35. Ma L, Corl BA. Transcriptional regulation of lipid synthesis in bovine mammary epithelial cells by sterol regulatory element binding protein-1. J Dairy Sci. 2012;95:3743-55

36. Shi H, Luo J, Zhu J, Li J, Sun Y, Lin X, Zhang L, Yao D, Shi H. PPAR Y regulates genes involved in triacylglycerol synthesis and secretion in mammary gland epithelial cells of dairy goats. PPAR Res. 2013;2013: 310948.

37. Li N, Zhao F, Wei C, Liang M, Zhang N, Wang C, Li QZ, Gao XJ. Function of SREBP1 in the milk fat synthesis of dairy cow mammary epithelial cells. Int J Mol Sci. 2014:15:16998-7013.

38. Xu HF, Luo J, Zhao WS, Yang YC, Tian HB, Shi HB, Bionaz M. Overexpression of SREBP1 (sterol regulatory element binding protein 1) promotes de novo fatty acid synthesis and triacylglycerol accumulation in goat mammary epithelial cells. J Dairy Sci. 2016;99:783-95.

39. Berger J, Moller DE. The mechanisms of action of PPARs. Annu Rev Med. 2002;53:409-35.

40. Echeverría F, Ortiz M, Valenzuela R, Videla LA. Long-chain polyunsaturated fatty acids regulation of PPARs, signaling: relationship to tissue development and aging. Prostaglandins Leukot Essent Fatty Acids. 2016;114:28-34.

41. de Paula Simino LA, de Fante T, Figueiredo Fontana M, Oliveira Borges F, Torsoni MA, Milanski M, Velloso LA, Souza Torsoni A. Lipid overload during gestation and lactation can independently alter lipid homeostasis in offspring and promote metabolic impairment after new challenge to highfat diet. Nutr Metab (Lond). 2017;14:16.

42. Yao CH, Fowle-Grider R, Mahieu NG, Liu GY, Chen YJ, Wang R, Singh M, Potter GS, Gross RW, Schaefer J, Johnson SL, Patti GJ. Exogenous fatty acids are the preferred source of membrane lipids in proliferating fibroblasts. Cell Chem Biol. 2016;23(4):483-93.

43. Oosterveer MH, van Dijk TH, Tietge UJ, Boer T, Havinga R, Stellaard F, Groen AK, Kuipers F, Reijngoud DJ. High fat feeding induces hepatic fatty acid elongation in mice. PLoS One. 2009;4(6):e6066.

44. Csapóa J, Martin TG, Csapó-Kiss ZS, Házasa Z. Protein, fats, vitamin and mineral concentrations in porcine colostrum and milk from parturition to 60 days. Int Dairy J. 1996;6(8-9):881-902.

45. Rosero DS, Boyd RD, Odle J, Heugten EV. Optimizing dietary lipid use to improve essential fatty acid status and reproductive performance of the modern lactating sow: a review. J Anim Sci Biotechno. 2016;7:34.

46. Bai YS, Wang CQ, Zhao X, Shi BM, Shan AS. Effects of fat sources in sow on the fatty acid profiles and fat globule size of milk and immunoglobulins of sows and piglets. Anim Feed Sci Tech. 2017;234:217-27. 
47. Jin C, Fang Z, Lin Y, Che L, Wu C, Xu S, Feng B, Li J, Wu. Influence of dietary fat source on sow and litter performance, colostrum and milk fatty acid profile in late gestation and lactation. Anim Sci J 2017;88(11):1768-1778.

48. Quiniou N, Richard S, Mourot J, Etienne M. Effect of dietary fat or starch supply during gestation and/or lactation on the performance of sows, piglets' survival and on the performance of progeny after weaning. Animal. 2008;2(11):1633-44.

Ready to submit your research? Choose BMC and benefit from:

- fast, convenient online submission

- thorough peer review by experienced researchers in your field

- rapid publication on acceptance

- support for research data, including large and complex data types

- gold Open Access which fosters wider collaboration and increased citations

- maximum visibility for your research: over $100 \mathrm{M}$ website views per year 